Public Health Medicine Committee British Medical Association

Cite this as: BMJ2022;376:0305 http://dx.doi.org/10.1136/bmj.0305 Published: 03 February 2022

\section{Public health: invisible in plain sight}

\author{
Ishani Kar-Purkayastha consultant in public health
}

My daughters were seven and four when the first wave of the pandemic hit in March 2020. In those early weeks, we didn't see much of each other. Even though we were in the same physical space, I was caught up in work. They understood. They coped remarkably. And in the evenings, hazy with exhaustion and uncertainty, they were keen to join with everyone else, clapping and cheering, distanced but together, in giving their thanks for the NHS and other key workers.

It was one of those evenings, that the older of my two daughters turned to me, and asked, "And public health. Right?” I nodded because I could see how much it mattered to her. "Then why doesn't anyone say public health?” She shouted out then, “Thank you, NHS. Thank you, public health.” Her little sister followed suit. But their voices were small and their words dispersed before they could take hold.

It mattered to them because, I suppose, in some way they wanted to know that my absence in their lives, through that period of uncertainty and worry, had purpose.

Though it might seem trivial, the lack of recognition that they intuitively understood is telling of a predicament in which the public health profession finds itself. It remains obscure, even in the throes of a global health emergency.

A BMA survey of public health doctors in the UK, published last year, highlighted that 75 per cent described their levels of fatigue and exhaustion as higher than normal, and 48 per cent reported feelings of depression, anxiety, stress, or other mental health conditions. Many said that they felt invisible.

Through the pandemic, there has been little meaningful recognition of the contribution made by the vast majority of the public health workforce. In England, even in the implementation of the covid-19 vaccine programme-immunisations being a well recognised public health intervention-the crucial role of public health professionals has not been prominent in public discourse.

This lack of visibility at a time when public health measures have been critical, is problematic. Poor recognition is often synonymous with being undervalued, and this in turn creates a cultural context in which systematic financial underinvestment, of the kind that we have seen in public health in recent years, is legitimised. This underinvestment is a matter of international concern as noted by the director general of the WHO, Tedros Adhanom Ghebreyesus, in his closing remarks at the World Health Assembly in November 2020. ${ }^{2}$

But by far the most worrying aspect of the invisibility that the public health profession is experiencing, is that we are invisible in plain sight. This is due in part to the lack of opportunity for the profession to present a consensus view that is distinctly and separately articulated within the public space, and not simply subsumed within public policy.

Policy is of course constituted from much more than public health evidence. The complexity of the research policy interface has been well described. ${ }^{34}$ However, the boundaries should be clear to everyone.

Calls for an independent public health voice have persisted through multiple public health systems and re-organisations over time. Back in 2013, the then director of the US Centers for Disease Control and Prevention, Thomas Frieden cited "Promoting free and open information" at the top of a list describing "Potential public health actions of a responsive government." ${ }^{5}$ Coincidentally, at around the same time, calls for independence were being mirrored in England as much of the public health system was being reorganised and embedded much more closely within government.

Concerns around professional independence have now re-surfaced ${ }^{67}$ A recent analysis of public health messaging during the pandemic illustrated the pitfalls of a politicised public health voice in maintaining public trust. ${ }^{8}$ In a crowded information marketplace where truth and misinformation jostle for attention, the lack of a single independent authoritative public health voice hinders the delivery of credible, trusted public health advice. And, while polling data continues to show high levels of public trust in scientists and doctors compared with politicians, the Wellcome Global Monitor 2020 found that globally people were not sure their governments valued scientific advice. ${ }^{9}$ Furthermore, notwithstanding assurances that public health professionals are free to "speak truth to power," where this advice is given privately, it inevitably loses transparency.

There is, as well, a moral imperative. Published codes of ethics, such as that adopted by the American Public Health Association, and The UK Faculty of Public Health in its Good Public Health Practice Framework, make clear that honesty, trust, and objectivity in decision making are critical. Furthermore, public health professionals should be free to take a position based on ethical analysis that balances autonomy, non-maleficence, beneficence, and justice at a population level. As Kass wrote in 2001, the ethically acceptable option may not be the politically preferable option at a given time. ${ }^{10}$ Neither is it acceptable that a democratic mandate, even taken as a proxy for "autonomy," should always take primacy, particularly if harms may be experienced by some parts of the population, as seen in increased health and social inequalities due to austerity measures implemented by governments across the world in the aftermath of the 2008 economic crisis, 
a situation in which public health voices were notably absent. ${ }^{11}$

What this pandemic has made abundantly clear is that the need for public health action is more urgent than ever. It also gives us an opportunity to look again at how we ensure that the public health profession can have a collective independent voice.

Competing interests: I am employed by the Office for Health Improvement and Disparities and am a member of the British Medical Association, Public Health Medicine Committee. My piece is, in part, informed by reflections on my work on the PHMC survey of public health doctors undertaken at the end of 2020 .

Provenance and peer review: not commissioned, not peer reviewed

1 Tonkin T. Public health doctors 'completely shattered'. British Medical Association News and Opinion. 2021 Jan 7. https://www.bma.org.uk/news-and-opinion/public-health-doctors-completelyshattered

2 Ghebreyesus TA. WHO Director-General's closing remarks at the World Health Assembly - 13 November 2020 https://www.who.int/director-general/speeches/detail/who-director-general-sclosing-remarks-at-the-world-health-assembly-13-november-2020

3 Brownson RC, Chriqui JF, Stamatakis KA. Understanding evidence-based public health policy. Am J Public Health 2009;99:1576-83. doi: 10.2105/AJPH.2008.156224. pmid: 19608941

4 Malekinejad M, Horvath H, Snyder H, Brindis CD. The discordance between evidence and health policy in the United States: the science of translational research and the critical role of diverse stakeholders. Health Res Policy Syst 2018;16:81.

doi: 10.1186/s12961-018-0336-7. pmid: 30115085

5 Frieden TR. Government's role in protecting health and safety. N Engl J Med 2013;368:1857-9. doi: 10.1056/NEJMp1303819. pmid: 23593978

6 Salwa J, Robertson C. Designing an Independent Public Health Agency. N Engl J Med 2021;384:1684-7. doi: 10.1056/NEJMp2033970. pmid: 33951378

7 Toff P. Public health system's independence concerns persist. British Medical Association News and Opinion. 2021 April 28. https://www.bma.org.uk/news-and-opinion/public-health-system-sindependence-concerns-persist

8 Smith V, Wanless A. Unmasking the Truth: Public Health Experts, the Coronavirus and the Raucous Marketplace of Ideas. Carnegie Endowment for International Peace 2020 Jul 16. Available from: https://carnegieendowment.org/2020/07/16/unmasking-truth-public-health-experts-coronavirusand-raucous-marketplace-of-ideas-pub-82314

9 The Wellcome Trust. Wellcome Global Monitor 2020: Covid-19. 2021 Nov 29. Available from: https://wellcome.org/reports/wellcome-global-monitor-covid-19/2020

10 Kass NE. An ethics framework for public health. Am J Public Health 2001;91:1776-82. doi: 10.2105/AJPH.91.11.1776. pmid: 11684600

11 Karanikolos M, Mladovsky P, Cylus J, etal. Financial crisis, austerity, and health in Europe. Lancet 2013;381:1323-31. doi: 10.1016/S0140-6736(13)60102-6. pmid: 23541059 